\title{
Power Quality Observations at a Light Industrial Site
}

\author{
Hamish Laird, Student Member, IEEE, Simon Round, Member, IEEE, Richard Duke, Member, IEEE \\ Alister Gardiner.
}

\begin{abstract}
This paper deals with observations of events that occur in the power system and could effect power quality at a winery. Power system incidents recorded at the site are presented. The impact of the equipment, which includes large induction motors, power factor correction capacitors and halfwave rectifier induction motor heaters on the supply system is described. The disturbance to equipment operation caused by system events such as sags are also detailed. In order to gauge the effect of the power events at the site the opinions of the customer and the supply company on the power quality were sought. These opinions are reported and in general, the events recorded and described caused little detriment to the customers power quality.
\end{abstract}

Index Terms-Power quality, Industrial site, Sags, Resonance, Power factor correction capacitors, Induction motor start transients.

\section{INTRODUCTION}

Power quality is a very important area of research since unreliable electrical supply can have large economic impact. This was amply demonstrated by the recent power outages in Auckland, New Zealand. In order to evaluate power quality it is necessary to study the events and operating conditions that occur in electrical supply networks and the effect these have on electrical equipment. Power quality surveys have been performed in Canada [1], the USA [2] and also in other countries. In these surveys large numbers of events have been collected and a statistical model of the power quality environment has been produced. Methods to determine the number of voltage sag events from network topology have also been developed [3] and the relationships between retained voltage and sag incident numbers have been investigated [4, 5]. Recent studies have turned attention to the power quality costs with methods being developed to estimate the mean and statistical distribution of costs for both commercial and industrial consumers [6].
The development of such models of the power quality environment and the associated costs are very important. Site monitoring and the site survey where disturbances can be correlated to site power problems are an integral part of determining the power quality environment. This is because they show the power quality effect of power system incidents [7]. In New Zealand the low population density means that loads are often a large distance from generation, with no redundancy in the supply. This weak grid situation makes the system power quality a major concern.

The power quality of a winery has been monitored with automatic recording equipment for 12 months. This has been part of a cooperative effort between the customer (the winery operator), the supply company, a government sponsored research and development company, a generating company and a university. The aim of this project is to research and improve power quality at the site. The winery manager describes operation of the winery as "flexible winemaking". This involves making full use of load switching to minimise energy costs. The site is supplied with both electricity and gas (methane) with the gas used only for water heating. The electrical power consumption is seasonal as all grapes are processed in a four week period in April and May. This period is called the vintage and the load at this time is $700 \mathrm{~kW}$. During the rest of the year the site has a lower electric power consumption of approximately $100 \mathrm{~kW}$.

The purpose of the study, this paper presents, is to investigate the power quality at the industrial site. The benefits are the collection of real site data for use as power quality incident examples in future research and the forming of an impression of the level of understanding of power quality in industry. Other benefits include the education of industry people on power quality issues and the establishment of relationships to ensure an ongoing effort into power quality management.

This paper describes the characteristics of the site loads and the transmission system connecting the site to the supply company's network. The effect that the AC system disturbances have on the loads is then detailed. The opinions of the customer and the supply company regarding the electric power quality at the site are then discussed. Solutions to the possible power quality problems and conclusions are then presented.

\section{Site EquiPMEnt, CURRENT AND Voltage WAVEForms}

The AC supply network to and within the winery is shown in Figure 1. 


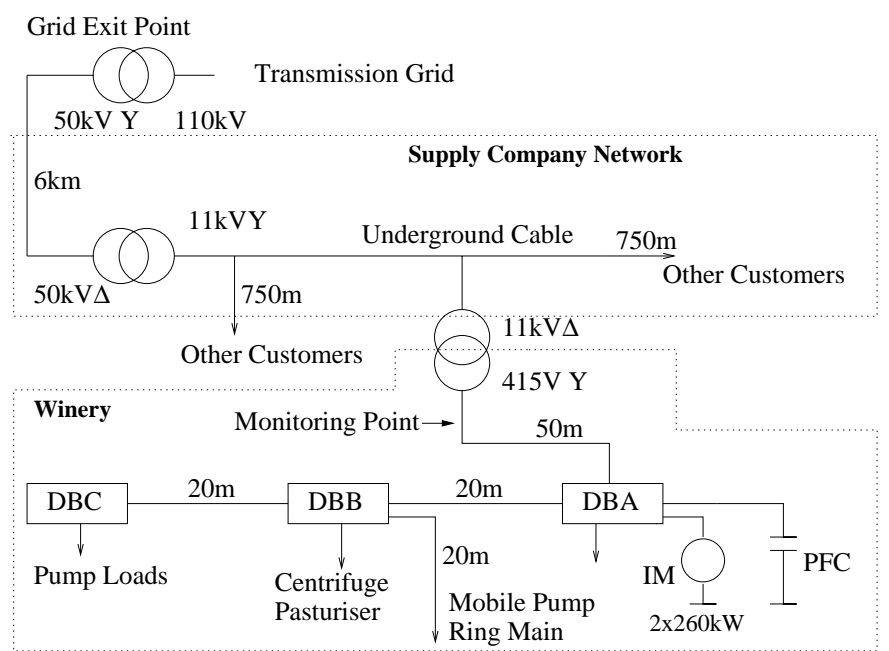

Figure 1. Winery Site and AC Supply System

The site is supplied with electricity through a $1 \mathrm{MVA}, 11 \mathrm{kV}$ to $415 \mathrm{~V}$, transformer and the power quality recording equipment monitors the incoming current and voltage at the $415 \mathrm{~V}$ entry point to the site. The transmission network connection is a $110 \mathrm{kV}$ single line spur from the transmission grid. The grid exit point is into a $50 \mathrm{kV}$ overhead line sub-transmission network that supplies the $50 \mathrm{kV}$ to $11 \mathrm{kV}$ transformer. The $11 \mathrm{kV}$ is reticulated with underground cables to sites in a light industrial area. Although the system is not physically radial it is configured that way electrically as no ring connections are made at the $50 \mathrm{kV}$ or $11 \mathrm{kV}$ level. The winery transformer is connected approximately $750 \mathrm{~m}$ from the $50 \mathrm{kV}$ to $11 \mathrm{kV}$ transformer and a cable feeds the $415 \mathrm{~V}$ to the main distribution board, DBA. There are two other distribution boards. DBB supplies the Programmable Logic Controller (PLC) controlled pasteuriser, the $22 \mathrm{~kW}$ centrifuge, the mobile pump ring main and two vacuum filters, while DBC connects the grape bag presses and four $5 \mathrm{~kW}$ slurry pumps for moving pressed grapes. Residual current devices (RCD), that protect both equipment and staff, are installed on the mobile pump ring main. The main distribution board, DBA, feeds two refrigeration compressors that are powered by $260 \mathrm{~kW}$ induction motors. Power factor correction capacitors and their associated controller are also connected at this point. The winery is open to the elements, having no roof except the building containing the compressors. A large amount of water is used in cleaning the site. A particular problem is water ingress into the induction motors that drive the mobile pumps. Water ingress has also been a problem in the compressor motors. Two motor heating units are connected at DBA to ensure that the compressor motor operating temperature is maintained. This prevents water lowering the insulation level to a point where it will break down.

\section{A. Induction Motor Start Transients}

The main operation performed at the site is pumping of both liquids and solid-liquid mixtures. Most of the pumps are driven by direct on-line connected induction motors. The largest electrical loads are the two refrigeration compressor induction motors. These motors are started under no load and each has starting current of 1700 Arms. Both motors have water resistor starters to lower the start current. This large start current, Figure 2(a), causes a $10 \%$ drop in the supply voltage, (as shown in Figure 2(b)) which the customer has reported noticing as a flicker in the lighting.
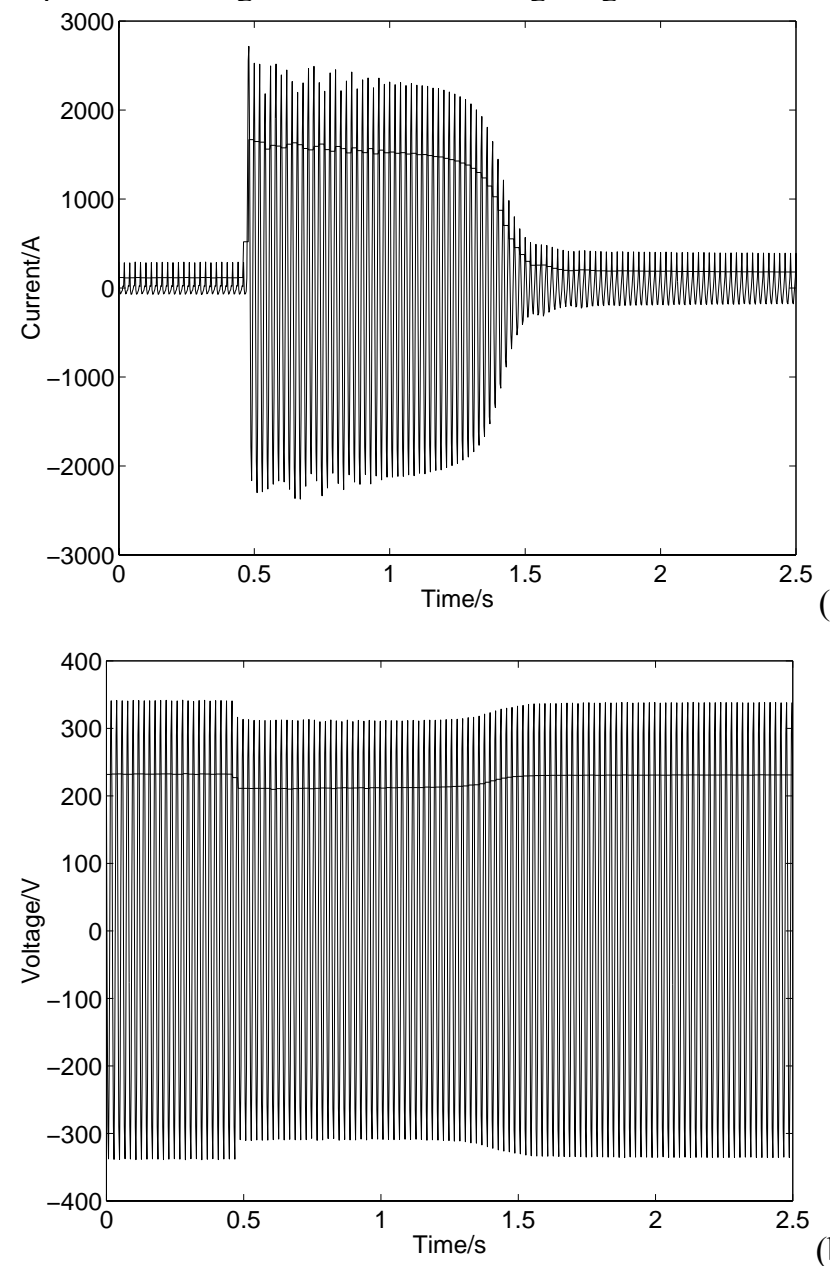

Figure 2. Induction Motor Start Transient (a) Motor Current (b) Supply Voltage (Instantaneous and RMS values)

\section{B. Induction Motor Heating Units}

The principal harmonic current producing loads on the site are the two induction motor heating units. One unit is connected to each refrigeration compressor motor. These units half-wave rectify the $\mathrm{AC}$ to produce a $\mathrm{DC}$ current that keeps the motor at operating temperature. The units are connected line to line and are switched out with a contactor when the motor runs. The electrical circuit of the heaters is shown in Figure 3. Two phases of the induction motor stator winding are used as a resistive heating element and the stator inductance, $\mathrm{L}_{\mathrm{S}}$, limits the rate of rise of current. The current control system controls the thyristor firing angle to maintain a relatively constant heating current. This can be seen in Figure 4 (which shows the typical AC side current and line to line voltage) where the thyristor is fired just before the voltage zero crossing. The total current (for two heater units) has a peak current of 600 Amps and an RMS value of 170 Amps. The two units are connected to the same phases (line to line) and conduct 
concurrently. This means each unit carries half the total current shown in Figure 4.

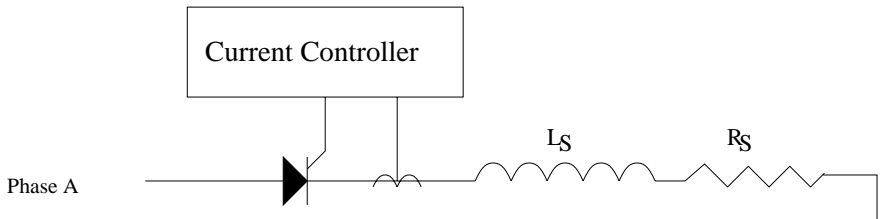

Phase B

Figure 3. Induction Motor Heating Unit Circuit Diagram

The units are half-wave controlled rectifiers having only one thyristor and they produce DC, odd and even harmonics in the AC current. The lack of half-wave symmetry indicates that there are even harmonics and a DC component present.

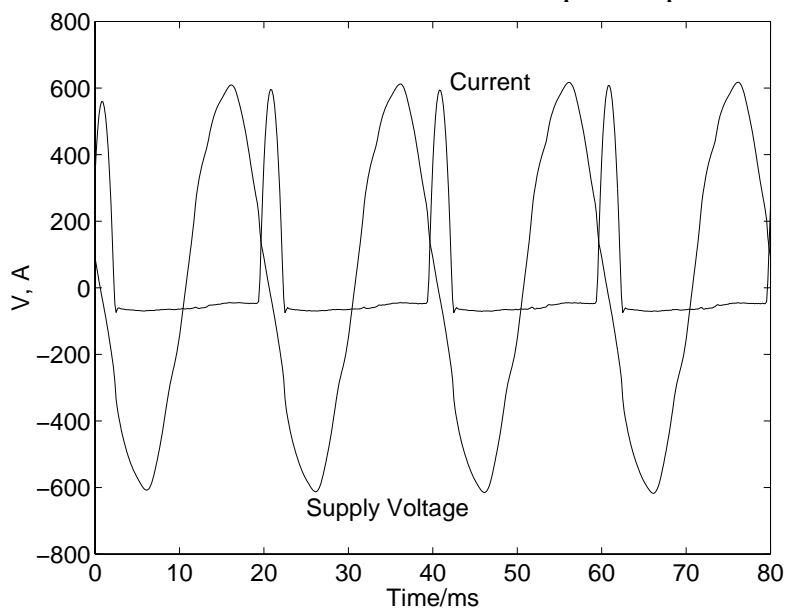

Figure 4. Induction Motor Heating Unit Current and System Line to Line Voltage

The frequency spectrum of the heater current is shown in Figure 5. There is no DC component shown on the spectrum, as the current sensors are current transformers that are not capable of measuring the DC component. The presence of the DC current component was confirmed by on site measurement with a meter capable of DC current measurement. The even harmonic content is shown and the presence of these means that a system resonance at or near an even harmonic could be excited by this waveform. A current without even harmonics could not excite such a resonance.

The DC current has impact on transformer operation as it produces a DC MMF that will offset the magnetising hysteresis of the transformer core. If the offset is large enough to drive the core sufficiently into saturation the magnetising current will increase and this could cause transformer overheating and possibly failure. As the rectifiers are connected line to line, the current has non-zero sequence triplen harmonic components that propagate through a stardelta supply transformer. Such harmonic currents may cause resonance that would not be excited by zero sequence triplen harmonics (produced by balanced harmonic loads) which are blocked by a star-delta transformer. The impact of the motor heating units is apparent when a voltage sag occurs (as shown in Figure 6). The relatively small voltage reduction of $15 \%$ causes a large transient excursion with a peak of 1200A along with one missed conduction cycle.

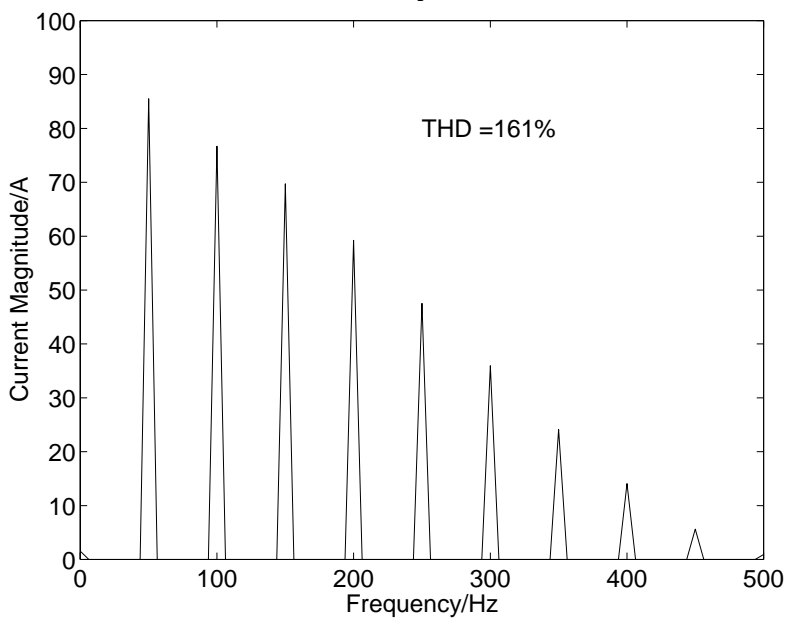

Figure 5. Induction Motor Heater Current Frequency Spectrum

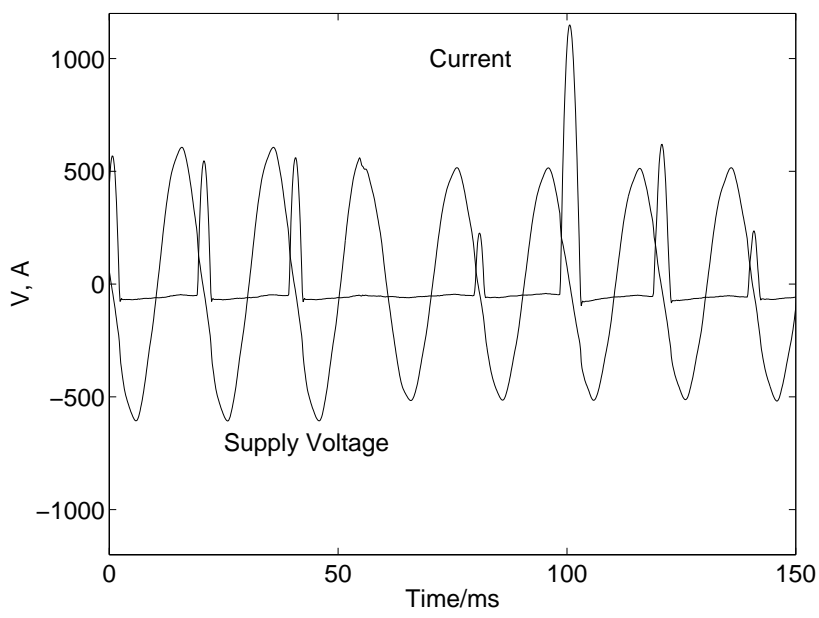

Figure 6. Induction Motor Heater Current and Supply Voltage during a Sag

\section{SYSTEM INTERACTIONS}

\section{A. Sags}

A large number of sags that have been recorded at the site cannot be correlated with events internal to the site. These sags vary in magnitude and duration. No statistical analysis is covered in this paper but the voltages during two sag events are shown in Figure 7 and Figure 8. The clearing times of the faults that caused these sags show that the faults occurred on the $50 \mathrm{kV}$ or the $11 \mathrm{kV}$ network. Correlation studies between faults on the transmission network and the sags measured at the monitored point show faults on the high voltage $110 \mathrm{kV}$ transmission network appear relatively infrequently as the cause of sags at the monitored site. 


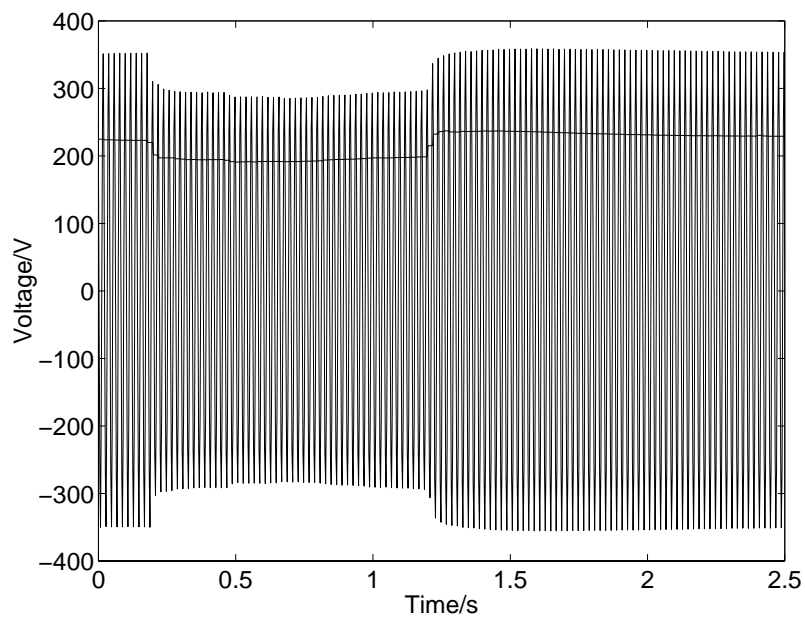

Figure 7. Sag Example 1 (Instantaneous and RMS Voltage)

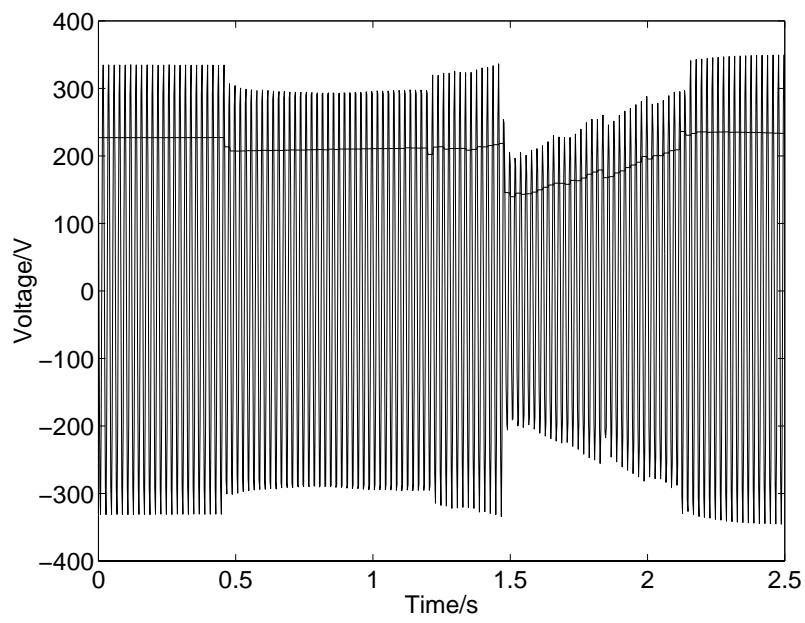

Figure 8. Sag Example 2 (Instantaneous and RMS Voltage)

\section{B. Capacitor Switching}

Power factor correction capacitor banks are switched to maintain close to unity power factor because the supply company's conditions of supply are such that VA demand is not a consideration as long as the power factor is unity. The supply company have mobile power factor loggers that are rotated through their industrial customers' sites on a regular basis to ensure compliance. The displacement power factor at the site is almost unity at all times except under very low load levels. A power factor correction capacitor switching event is shown in Figure 9. The initial switching transient is large with a 1400A peak. The transient disturbance is also apparent from the voltage waveform where the peak phase to neutral voltage reaches almost $600 \mathrm{~V}$. This transient is quickly damped away but a resonance now occurs which can be seen in the current in Figure 9(a).

\section{System Resonance}

The reticulation system feeds the light industrial area in a radial fashion with no ring connections. The system is often lightly loaded with the entire load on the $11 \mathrm{kV}$ feeder less than 1MVA. The installed distribution capacity for the $11 \mathrm{kV}$ feeder is 6.5MVA.

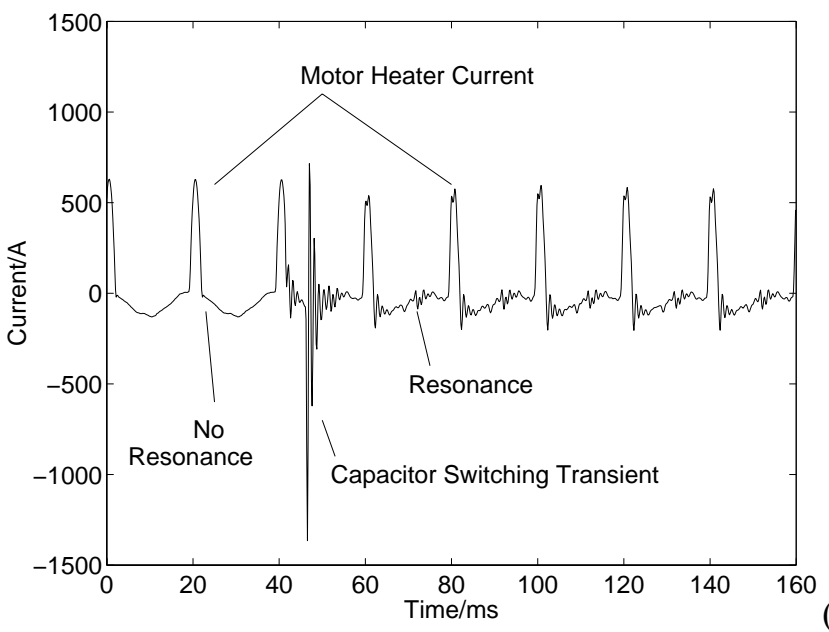

(a)

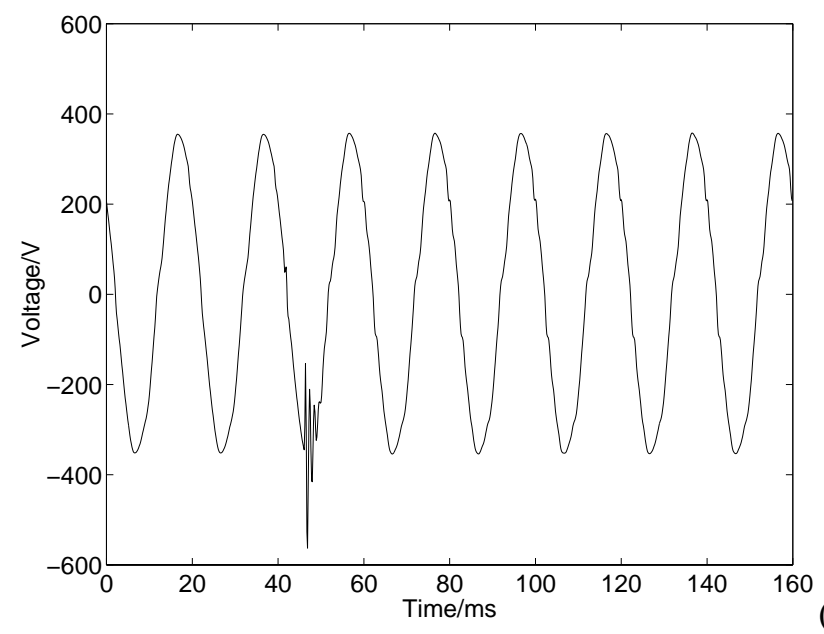

Figure 9. Capacitor Switching Transient (a) Current (b) Voltage

At the peak of the one-month vintage the winery's load is $700 \mathrm{~kW}$, while for more than 10 months the load is less than $100 \mathrm{~kW}$. As the network is very lightly loaded it is often underdamped at harmonic frequencies. The larger capacitance of cables compared with overhead lines and the unity power factor requirements means that the system has relatively large capacitance at all times. This large capacitance makes the resonant frequency relatively low. The system shows a resonance near $450 \mathrm{~Hz}$. This was determined by analysing transient events to find the frequency of oscillation when the system is excited by a transient change. It has been confirmed by a PSCAD simulation of a representative system model. The resonance can be seen in the current waveform in Figure 9. It is excited by the transient switching and occurs when power factor correction capacitors are switched in. The transient and the presence of the harmonic current excite the resonance and the lack of loading on the system contributes to the low damping of this oscillation. Supply company personnel have reported having a resonance problem near this frequency when installing ripple control equipment

\section{Perceptions of Power Quality}

In order to determine the interest and level of understanding of power quality meetings were held separately with the customer and the supply company. It was hoped that one 
meeting would include both the supply company and the customer, but this was not possible as an agreement to allow full disclosure of the findings had not been reached between the two parties. The problem preventing agreement was the customer's insistence that the generating company, a principal sponsor of the investigation, indemnify the customer for any monetary losses occurring as a result of the investigation. The generating company would not and could not do this. Agreement allowing full disclosure has yet to be made. The lack of agreement meant that the results of the investigation could only be released where there was no possibility of the supply company or customer seeking redress from any of the other parties involved. This meant that information regarding the site was released to the customer and that pertaining to the distribution network was released to the supply company. The lack of full disclosure has probably prevented the full benefit of the investigation being achieved.

\section{A. Customer's View}

The customer and the site contract electrician were interviewed and the site power quality was discussed. When asked about the site power quality the customer expressed concern that the quality was not as good as it could be. The customer recounted an incident that occurred in the previous vintage. An outage forced the dumping of grapes because they prematurely fermented. At that time the customer was concerned at the re-energisation policy, or lack of it, that the supply company used. The customer felt that the power was returned after other, less critical, customers had supply returned. The customer mentioned that an insurance claim had been made for the lost grapes. The customer has and continues to consider installing dedicated generation at the site and has also considered the possible use of co-generation. The seasonal nature of the operation was given by the customer as the reason for not pursuing these options. The customer is aware of the relatively large exposure to risk during the vintage.

The customer's technical expertise with regard to electric power systems was low as would be expected. The site electrician was very technically able with a good understanding of possible power quality problems.

\section{B. Supply Company's Perspective}

The supply company had greater technical expertise than the customer, but had very little knowledge of the nature of the electric power at the winery site. Supply company monitoring at the site is limited to revenue metering and the regular power factor monitoring to ensure compliance to power factor limits. The supply company personnel were unaware of the voltage level at the site. Engineers at the supply company reported reconfiguring their network to temporarily allow sensitive loads, such as a cable extruding plant, a dedicated $50 \mathrm{kV}$ to $11 \mathrm{kV}$ transformer. This indicates an awareness of possible power quality problems and their impact. There was considerable interest shown in the results of the investigation and there seemed to be a genuine desire to improve the level of service that they gave to the customers. Power quality improvement techniques such as removing trees that could cause faults are being pursued but as there is no sag incident monitoring and reporting, except this investigation, there is no quantitative review of the effects. The supply company are also dependent on the transmission network of the transmission company and at times find themselves feeling the wrath of their customers without having any way to correct the problem.

\section{Discussion AND SOlutions to Power Quality PROBLEMS}

The most surprising situation at this site is the occurrence of events and conditions that could indicate low power quality but the lack of reported power quality related problems. Such findings are useful and interesting as they show those with non-industrial backgrounds the nature of actual site electrical power systems. They also show that the current and voltage waveforms cannot always be used to predict or indicate that the customer will have power quality problems.

The induction motor heater unit current harmonics are large and the presence of even harmonics is unusual. The apparent lack of problems that the DC component of the heater current causes is perhaps fortuitous as the resulting transformer MMF offset could cause transformer damage through saturation. No such damage has occurred and the transformer operating temperature during the site survey was $38 \mathrm{C}$. The fact that the heater units operate only when the site load is low means any adverse transformer heating from saturation is offset by reduced heating due to the low load. Configuring the rectifiers to produce a half wave symmetric current waveform would eliminate the DC current produced by the induction motor heaters. One way to do this is to reverse the phase connection of one of the induction motor heaters. The two heater units would then conduct in opposite half cycles and together would produce a half-wave symmetric waveform. This would decrease the peak current and remove the even harmonic currents. The current waveform would however not be halfwave symmetric at all times as the heating units are on occasion operated separately. However the maximum level of DC current flowing in the transformer would be lowered as DC current would flow only when one heater was operating.

The induction motor start transient typically causes a $10 \%$ drop in the site voltage. A solid-state or star-delta starter could lower the start current and so lower the voltage drop. The cost involved may not be justifiable as the motor start induced sag caused no reported problems other than the customer's concern about the "flick" in the lights. Another option to prevent the voltage drop is to control the motor run up with an adjustable speed drive. This again is an expensive option and is probably not worth pursuing. A more reasonable approach is to ensure the customer is aware of the possible consequences of the voltage dip, such as nuisance tripping and PLC malfunction. This awareness will ensure that any problems that the dips do cause will be noted.

The capacitor switching and the associated resonance indicate that the AC system is not well damped, which is consistent with the loading figures for the system. The resonance could be damped with a harmonic filter tuned to the resonant 
frequency or the power factor correction capacitor banks could be tuned by adding series inductors. As these solutions are expensive it is unlikely they will be adopted and the lack of reported problems means that no solution is required.

The attitude of the customer and the supply company to power quality improvement is on the whole positive with both having quite an open view at a technical level. However the inability of all parties to resolve commercial difficulties was unfortunate. As a result full disclosure was not possible, leaving potential power quality problems unaddressed. The supply company has limited knowledge of their delivered power quality and so are interested in any network information that can be provided. The customer is very keen to improve power quality, as the exposure to risk at the site is very high because of the concentration of operation in the vintage period. The lack of specific repeating incidents at the site does little to prevent the customer feeling that power quality is low and could be improved. Such an attitude is reasonable, as it is the customer's purpose to achieve the best results for their products and so they demand the best possible service from their suppliers.

On a technical level the investigation has been worthwhile for the authors, as real industrial data has been recorded, but perhaps not for the customer and the supply company. The lack of openness has limited the benefit for the customer and the supply company. The level of technical understanding encountered was not completely as was expected. The supply company has degree-qualified engineers who were aware of the principles of power quality. The customer had little technical knowledge. The level of technical expertise that the contract electricians had was above that expected. This is worth noting as they are the first to deal with everyday power quality problems.

\section{CONCLUSIONS}

Power quality has been investigated over a year with automated recording of the events that occurred at the site. From the recorded events and a site survey the equipment installed at the site has been identified and the current that this equipment draws has been determined along with the effect of the loads on the supplied voltage. The events that could have an effect on power quality are the large induction motor start currents, and the motor heaters' harmonic currents. These include DC, odd and even harmonics. The DC current seems to have no adverse effect on the supply transformer, but it would be wise to remove this current if possible. The large start current for the two large induction motors causes a $10 \%$ drop in the site voltage but has no reported adverse effect and so the use of other starting techniques, such as controlled current starting, is probably unnecessary. Other events include capacitor switching where a large $1400 \mathrm{Amp}$ transient occurs and continued oscillation when the capacitor bank is switched in. This oscillation is due to the large capacitance connected to the network to meet power factor requirements, the capacitance of the underground cable and the network's low loading. There were no reported power quality problems at the site except power outages that concern the customer as the entire wine production occurs in the one-month vintage period. As such exposure to risk is very high at this time. The customer's impression is that power quality could be better because of this exposure and options such as dedicated generation and co-generation have been and continue to be considered.

This power quality investigation has raised the awareness of the industrial customer and the supply company about power quality issues. It has also been valuable for the authors. This data shows that the power quality at a site can be relatively high in terms of customer satisfaction and yet there can still be events and conditions like the induction motor start, capacitor switching and DC induction motor heater current that indicate low power quality.

\section{ACKNOWLEDGMENTS}

The Authors acknowledge the support of The New Zealand Foundation for Research, Science and Technology.

\section{REFERENCES}

[1] D. O. Koval and M. B. Hughes, "Canadian National Power Quality Survey: Frequency of Industrial and Commercial Voltage Sags," IEEE Transactions on Industry Applications, vol. 33, no. 3, pp. 622-627, 1997.

[2] D. S. Dorr, M. B. Hughes, T. M. Gruzs, R. E. Jurewicz, and J. L. Mclaine, "Interpreting Recent Power Quality Surveys to Define the Electrical Environment," IEEE Transactions on Industry Appliactions, vol. 33, no. 6, pp. 1480-1487, 1997.

[3] M. H. J. Bollen, T. Tayjasanant, and G. Yalcinkaya, "Assessment of the Number of Voltage Sags Experienced by a Large Number Industrial Customer," IEEE Transactions on Industry Appliactions, vol. 33, no. 6, pp. 1465-1471, 1997.

[4] N. Abi-Samra, A. Sohn, G. Gurlaske, and W. Malcom, "Analysis of Voltage Sags on Distribution Systems -Part 1," Power Quality Solutions/Alternative Energy Conference, Las Vegas Nevada, pp. 4558, 1996.

[5] N. Abi-Samra, A. Sohn, G. Gurlaske, and W. Malcom, "Analysis of Voltage Sags on Distribution Systems -Part 2," Power Quality Solutions/Alternative Energy Conference, Las Vegas Nevada, pp. 5972, 1996.

[6] M. J. Sullivan, T. Vardell, and M. Johnson, "Power Interuption Costs to Industrial and Commercial Consumers of Electricity," IEEE Transactions on Industry Appliactions, vol. 33, no 6, pp. 1448-1458, 1997.

[7] K. M. Michaels, "Sensible Approaches to Diagnosing Power Quality Problems," IEEE Transactions on Industry Appliactions, vol. 33 no 4, pp. 1125-1130, 1997.

\section{BIOGRAPHIES}

Hamish Laird graduated from the University of Canterbury, Christchurch, New Zealand with a BE(Hons) and ME in 1990 and 1992 respectively. He is currently studying for a $\mathrm{PhD}$ at the same university.

Simon Round holds a BE(Hons) and $\mathrm{PhD}$ from the University of Canterbury where he is currently a lecturer. His research interests include power electronics, active filtering and motor drives.

Richard Duke holds a BSc, BE(Hons), $\mathrm{ME}$ and $\mathrm{PhD}$ all from the University of Canterbury where he is currently Head of the Electrical and Electronic Engineering Dept.

Alister Gardiner is Electrotechnology Group Manager at Industrial Research Limited, Christchurch, New Zealand. 